\title{
Clinical Applications of Adiponectin Measurements in Type 2 Diabetes Mellitus: Screening, Diagnosis, and Marker of Diabetes Control
}

\author{
Nabila A. Abdella $\mathbb{D}^{1}$ and Olusegun A. Mojiminiyi $\mathbb{D}^{2}$ \\ ${ }^{1}$ Department of Medicine, Faculty of Medicine, Kuwait University, Safat, Kuwait \\ ${ }^{2}$ Department of Pathology, Faculty of Medicine, Kuwait University, Safat, Kuwait \\ Correspondence should be addressed to Nabila A. Abdella; nabdella12@yahoo.com
}

Received 27 December 2017; Accepted 2 June 2018; Published 5 July 2018

Academic Editor: Manlio Vinciguerra

Copyright () 2018 Nabila A. Abdella and Olusegun A. Mojiminiyi. This is an open access article distributed under the Creative Commons Attribution License, which permits unrestricted use, distribution, and reproduction in any medium, provided the original work is properly cited.

\begin{abstract}
Background. Adipose tissue-derived adiponectin has pleiotropic protective effects with suppression of inflammatory and metabolic derangements that may result in insulin resistance, metabolic syndrome, type 2 diabetes mellitus (T2DM), and cardiovascular disease. The aim of this study was to evaluate adiponectin as a diagnostic marker of T2DM and diabetes control. Methods. Fasting adiponectin, insulin, glucose, and HbAlc were determined in 376 patients with known T2DM and 575 subjects with undiagnosed diabetes but with family history of T2DM. Clinical and anthropometric data were recorded. Subjects were classified on the basis of degree of adiposity, insulin resistance (IR), and achievement of target HbA1c levels. Receiver operating characteristic (ROC) curve analysis was used to examine the diagnostic performance for undiagnosed DM. Results. In undiagnosed subjects, adiponectin was significantly lower in subjects with IR and diabetic subjects compared with those without. The area under the adiponectin ROC curve for diagnosis of DM was 0.740. In known T2DM subjects, those with good control had significantly higher adiponectin (8.6 versus $7.4 \mu \mathrm{g} / \mathrm{mL}$ ) compared to subjects with poor control. Conclusions. Adiponectin levels are associated with better glycemic control and could be a useful adjunct for screening for IR and T2DM. Therapeutic measures that increase adiponectin levels might be valuable targets for improving diabetes control and decreasing complications.
\end{abstract}

\section{Introduction}

Type 2 diabetes mellitus (T2DM) is highly prevalent and is one of the leading causes of mortality and morbidity worldwide. T2DM is characterized by insulin resistance or impaired insulin secretion often in association with obesity which causes insulin resistance through secretion of various adipocyte-derived proteins. Adiponectin, a bioactive adipocytokine exclusively secreted by mature adipocytes in adipose tissue possesses anti-inflammatory, antiatherogenic, and insulin-sensitizing properties. It is the most abundant adipocytokine synthesized by adipocytes and the only adiposespecific protein that is negatively regulated in obesity [1-3]. Various cross-sectional studies have documented the association of low adiponectin levels with obesity, insulin resistance, metabolic syndrome (MetS), and progression from prediabetes to T2DM.

The pleiotropic protective effects of the adiponectin occurs via several postulated mechanisms that could, potentially, reduce the risk of T2DM and its associated complications. Some of the multiple anti-inflammatory and antiatherogenic effects of adiponectin involve vascular endothelial cell survival and activation through inhibition of TNF- $\alpha$ signaling [4] and regulation of endothelial nitric oxide synthase (eNOS). Adiponectin exerts potent insulin-sensitizing action through fatty acid oxidation, increased energy consumption, and stimulation of insulin secretion $[2,5]$. There is strong accumulating evidence from several prospective studies that showed low adiponectin levels as a predictor of the incidence of T2DM $[6,7]$. Adiponectin has been shown to significantly correlate 
inversely with obesity, hypertension, dyslipidemia, fasting plasma glucose levels, and insulin resistance [8-11], which are known risk factors for subsequent development of T2DM. Given the prominent biological functions and associations of adiponectin as a protective adipocytokine against T2DM, this study assesses the potential roles of adiponectin as a useful clinical diagnostic indicator of incident diabetes among individuals at increased risk as well as diabetes control among T2DM patients.

\section{Materials and Methods}

2.1. Subjects and Clinical Features. The study subjects were recruited from polyclinics, specialized diabetes clinics, and hospitals in Kuwait where subjects with T2DM were advised to invite their first-degree relatives (FDR) for screening to assess their risks of developing T2DM as described previously [12]. 575 apparently healthy FDR of patients with T2DM were studied. To evaluate adiponectin as a marker of DM control, we studied 376 patients with known T2DM duration of $12.4 \pm 8.1$ years. Prediabetes and T2DM were confirmed according to the criteria of the American Diabetes Association [13]. For the first-degree relatives, criteria for inclusion in the study were both parents, one parent, and/ or a sibling with T2DM and absence of any hematologic, genetic (especially presence of hemoglobin variants), and illness-related factors that could affect or interfere with the estimation of HbAlc. None of the study subjects was taking any medication at the time of the study. None of the study subjects had a history of surgery on reproductive organs (e.g., oophorectomy), and female subjects were specifically asked if their menstruation had stopped. None of the female study subjects was menopausal at the time of the study. The study was approved by the Ethics Committees of the Faculty of Medicine, Kuwait University, and the Ministry of Health, Kuwait, and performed in accordance with the Declaration of Helsinki. All subjects gave informed voluntary consent to participate in the study.

Height was measured to the nearest $0.1 \mathrm{~cm}$ and body weight to the nearest $0.1 \mathrm{~kg}$ using a stadiometer, and the body mass index (BMI) $\left(\mathrm{kg} / \mathrm{m}^{2}\right)$ was calculated [12]. The body mass index (BMI) was calculated according to the following formula: weight in kilograms divided by the square of the height in meters. Patients with BMI $>30 \mathrm{~kg} / \mathrm{m}^{2}$ are classified as obese and those with $\mathrm{BMI}<25$ are classified as normal. Those with BMI $>24.9$ to $<30$ are classified as overweight. Waist circumference (WC) was measured half way between the xiphisternum and the umbilicus at the point corresponding to the maximal abdominal protuberance. Two consecutive measurements of systolic blood pressure (SBP) and diastolic blood pressure (DBP) were taken from each subject after at least $10 \mathrm{~min}$ rest.

\subsection{Laboratory Methods}

2.2.1. Assays. As described previously [12], fasting plasma adiponectin was measured using a commercially available enzyme-linked immunoassay (ELISA) kit (Linco Research, Missouri, USA) with a sensitivity of $0.39 \mu \mathrm{g} / \mathrm{mL}$. The intra- and interassay coefficients of variation on pooled plasma specimen with adiponectin concentration of $8.2 \mu \mathrm{g} / \mathrm{mL}$ were $4.7 \%$ and $6.8 \%$, respectively.

Fasting serum insulin was determined on an automated analyzer Beckman DXI 800 (Beckman Corporation) using the paramagnetic particle chemiluminescence immunoassay method [12]. Insulin resistance was calculated using the homeostasis model assessment (HOMA-IR) using the HOMA2 calculator (version 2.2.2) downloaded from https://www.dtu.ox.ac.uk/homacalculator/download.php (Diabetes Trials Unit, Oxford). HOMA-IR $>2$ was used as the cut-off point for determination of insulin resistance [14]. The HOMA2 calculator also gives estimates of steadystate beta cell function (\%B) and insulin sensitivity (\%S).

$\mathrm{HbA1c}$ levels were measured using high-performance liquid chromatography on a TOSOH G8 analyzer (Tosoh Corporation, Tokyo, Japan) [12]. HbA1c values or fasting plasma glucose (FPG) based on ADA diagnostic criteria [13] was used to categorize the subjects as follows: normal subjects $-\mathrm{HbA} 1 \mathrm{c}<5.7 \%(<39 \mathrm{mmol} / \mathrm{mol})$ or $\mathrm{FPG}<5.6 \mathrm{mmol} / \mathrm{L}$; subjects with prediabetes-HbA1c 5.7\%-6.4\% (39-46 mmol/ $\mathrm{mol}$ ) or FPG $5.6-6.9 \mathrm{mmol} / \mathrm{L}$; subjects with diabetes-HbA1c $\geq 6.5 \%(\geq 48 \mathrm{mmol} / \mathrm{mol})$ or $\mathrm{FPG} \geq 7.0 \mathrm{mmol} / \mathrm{L}$.

FPG, alanine aminotransferase (ALT), total cholesterol (TC), triglycerides (TG), high-density lipoprotein cholesterol (HDL-C), apolipoprotein A1 (Apo-A1), and apolipoprotein B (Apo B) were analyzed on an automated analyzer (Beckman DXC 800, Beckman Corporation) [12]. Lowdensity lipoprotein cholesterol (LDL-C) was calculated using the Friedewald formula [15]. The formula is valid as long as $\mathrm{TG} \leq 4.5 \mathrm{mmol} / \mathrm{L}$.

2.3. Statistical Methods. IBM SPSS 19.0 software (IBM) was used for statistical analysis. Data are presented as mean \pm standard deviation (SD) unless otherwise specified. The Kolmogorov-Smirnov goodness-of-fit test was to test for normality of the data. Several variables (insulin, HOMA-IR, $\mathrm{B} \%$, and $\mathrm{TG}$ ) that diverged significantly from normal distribution were log transformed when parametric tests were used. Comparisons between two groups were performed with the Mann-Whitney $U$ test, and the Kruskal-Wallis analysis of variance was used to compare between more than two groups. The chi-square test was used to compare categorical variables. To determine the predictors of adiponectin, we performed linear and multivariate regression analysis with adiponectin as the dependent variable. All cardiometabolic variables were included in the multivariate stepwise regression model. Binary logistic regression analysis was performed to estimate the odds ratios (ORs) and 95\% confidence intervals (CIs) for the association between adiponectin and T2DM. We performed receiver operating characteristic (ROC) analysis on the usefulness of adiponectin for the detection of diabetes. $p<0.05$ was considered statistically significant for all analyses.

\section{Results}

3.1. General Results. 73 of 575 study subjects were found to have previously undiagnosed T2DM. Tables 1 and 2 
TABLE 1: Clinical and anthropometric characteristics of study subjects screened for glycemic status grouped by degree of adiposity.

\begin{tabular}{|c|c|c|c|c|}
\hline $\operatorname{BMI}\left(\mathrm{kg} / \mathrm{m}^{2}\right)$ & Normal $(\mathrm{BMI}<25)$ & Overweight (24.9-30) & Obese $(>30)$ & $p$ (Kruskal-Wallis) \\
\hline Age (yrs) & $25.7 \pm 8.2$ & $28.9 \pm 8.9$ & $31.8 \pm 8.8$ & $<0.0001$ \\
\hline $\mathrm{WC}(\mathrm{cms})$ & $83.8 \pm 9.2$ & $95 \pm 9$ & $108.7 \pm 12.6$ & $<0.0001$ \\
\hline $\mathrm{SBP}(\mathrm{mm} / \mathrm{Hg})$ & $109 \pm 10$ & $115 \pm 15$ & $116 \pm 13$ & 0.001 \\
\hline DBP (mm/Hg) & $69 \pm 8$ & $72 \pm 8$ & $74 \pm 7$ & $<0.0001$ \\
\hline TC (mmol/L) & $4.48 \pm 0.82$ & $4.93 \pm 0.98$ & $5.15 \pm 1.13$ & $<0.0001$ \\
\hline $\mathrm{TG}(\mathrm{mmol} / \mathrm{L})$ & $0.81 \pm 0.54$ & $1.09 \pm 0.72$ & $1.32 \pm 0.95$ & $<0.0001$ \\
\hline HDL-C (mmol/L) & $1.25 \pm 0.36$ & $1.18 \pm 0.33$ & $1.16 \pm 0.31$ & 0.23 \\
\hline LDL-C (mmol/L) & $2.79 \pm 0.71$ & $3.04 \pm 0.83$ & $3.34 \pm 0.92$ & $<0.0001$ \\
\hline ALT (IU/L) & $22.52 \pm 17.05$ & $24.63 \pm 15.34$ & $27.37 \pm 16.57$ & $<0.0001$ \\
\hline Insulin $(\mu \mathrm{U} / \mathrm{mL})$ & $5.38 \pm 4.68$ & $6.8 \pm 6.07$ & $10.86 \pm 9.47$ & $<0.0001$ \\
\hline S\% & $143.19 \pm 59.44$ & $122.24 \pm 54.92$ & $94.4 \pm 51.81$ & $<0.0001$ \\
\hline $\mathrm{B} \%$ & $87.55 \pm 36.83$ & $100.43 \pm 67.71$ & $111.05 \pm 54.5$ & $<0.0001$ \\
\hline HOMA-IR & $0.9 \pm 0.65$ & $1.07 \pm 0.74$ & $1.46 \pm 1.04$ & $<0.0001$ \\
\hline Glucose (mmol/L) & $5 \pm 0.99$ & $5.05 \pm 0.66$ & $5.22 \pm 1.03$ & 0.03 \\
\hline HbAlc (\%) & $5.88 \pm 0.83$ & $5.87 \pm 0.62$ & $8.75 \pm 26.39$ & 0.001 \\
\hline Adiponectin $(\mu \mathrm{g} / \mathrm{mL})$ & $8.95 \pm 3.82$ & $8.57 \pm 5.12$ & $6.82 \pm 2.97$ & $<0.0001$ \\
\hline
\end{tabular}

Abbreviations: WC: waist circumference; SBP: systolic blood pressure; DBP: diastolic blood pressure; TC: total cholesterol; TG: triglyceride; HDL-C: high-density lipoprotein; LDL-C: low-density lipoprotein; ALT: alanine aminotransferase; S\%: insulin sensitivity; B\%: beta cell function; HOMA-IR: homeostasis model assessment of insulin resistance; HbAlc: hemoglobin Alc. Data are presented as mean \pm standard deviation

summarize clinical and anthropometric parameters of study subjects screened for glycemic status grouped by degree of adiposity and T2DM, respectively. Subjects who were obese had significantly higher blood pressure, lipid profile, ALT, insulin, B\%, HOMA-IR, fasting glucose, and HbAlc levels and lower $\mathrm{S} \%$ compared to normal individuals. Adiponectin levels were significantly lower with increasing degree of adiposity (Table 1). In Figure 1, FDR screened for undiagnosed diabetes were categorized according to their state of IR. Subjects who were insulin resistant were found to have significantly reduced adiponectin concentrations (5.7 versus $8.1 \mu \mathrm{g} / \mathrm{mL}$ ) compared to subjects without IR. In Table 2, FDR diagnosed with T2DM had significantly higher WC, SBP, ALT, insulin, B\%, and HOMA-IR but significantly lower $S \%$ and adiponectin levels (6.9 versus $8.6 \mu \mathrm{g} / \mathrm{mL}$ ) compared to those subjects who did not develop T2DM.

Table 3 shows the clinical, anthropometric, and metabolic characteristics of known T2DM patients $(n=376)$ grouped according to their achievement of target $\mathrm{HbAlc}$ levels. T2DM patients with poor glycemic control ( $>53 \mathrm{mmol} / \mathrm{mol}$ ) had higher ALT, B\%, and HOMA-IR but significantly lower adiponectin levels $(7.4$ versus $8.6 \mu \mathrm{g} / \mathrm{mL})$ compared to subjects with good control $(<53 \mathrm{mmol} / \mathrm{mol})$.

3.2. Predictors of Circulating Adiponectin. The associations of adiponectin with cardiometabolic variables are shown in Table 4. With the exception of HbAlc, adiponectin was significantly associated with cardiometabolic variables. However, when all the cardiometabolic variables were included in the full model of regression analysis, the strongest significant predictors of circulating adiponectin were waist circumference, HDL-cholesterol, apolipoprotein A1, apolipoprotein $B$, and HOMA-IR.
3.3. Regression Analysis. Binary logistic regression analysis showed that adiponectin was significantly associated with T2DM with an odds ratio of 0.88 [95\% confidence interval (CI) $0.80-0.96 ; p=0.007]$.

3.3.1. Performance Characteristics for Detection of T2DM. Using the ADA glucose and $\mathrm{HbAlc}$ diagnostic criteria as reference, ROC curve (Figure 2) analyses for the use of adiponectin to detect T2DM showed that the area under the adiponectin curve was 0.740 (95\% CI $0.570-0.910)$. At the cut-off point of $7.5 \mu \mathrm{g} / \mathrm{mL}$, the diagnostic sensitivity and specificity of adiponectin for T2DM were $88 \%$ and $51 \%$, respectively.

\section{Discussion}

This study demonstrates the potential clinical significance of adiponectin measurements in T2DM. Our results confirm and extend those of several studies that demonstrated the protective role of high adiponectin levels with lower risk of T2DM and association of low adiponectin levels with risk factors for T2DM $[16,17]$ and subsequent cardiovascular complications associated with the disease $[18,19]$.

The significant progressive decrease in adiponectin (Table 1) in line with increasing degree of insulin resistance (Table 1 and Figure 1) with increasing degrees of obesity indicate the utility of adiponectin as a screening tool. Obesity is an important determinant of insulin resistance and a known risk factor for development of T2DM and cardiovascular disease. The significant associations of adiponectin with cardiometabolic risk factors (Table 4) show the usefulness for the identification of high-risk first-degree relatives of T2DM patients who tend to exhibit a higher propensity to be insulin resistant [20]. Hypoadiponectinemia 
TABLE 2: Clinical and anthropometric characteristics of subjects screened for type 2 diabetes mellitus.

\begin{tabular}{|c|c|c|c|}
\hline HbAlc & $\begin{array}{l}\text { Normal } \\
(<5.7 \%)\end{array}$ & $\begin{array}{c}\text { Undiagnosed } \\
\text { diabetes }(\geq 6.5 \%)\end{array}$ & $\begin{array}{l}p(\text { Mann- } \\
\text { Whitney } U)\end{array}$ \\
\hline Age (yrs) & $28.2 \pm 8.6$ & $32 \pm 9.7$ & 0.019 \\
\hline WC (cms) & $93.6 \pm 16.0$ & $104.6 \pm 14.7$ & $<0.0001$ \\
\hline $\mathrm{SBP}(\mathrm{mm} / \mathrm{Hg})$ & $113 \pm 13$ & $120 \pm 17$ & 0.005 \\
\hline $\begin{array}{l}\mathrm{DBP}(\mathrm{mm} / \\
\mathrm{Hg})\end{array}$ & $73 \pm 9$ & $73 \pm 10$ & 0.37 \\
\hline $\mathrm{TC}(\mathrm{mmol} / \mathrm{L})$ & $4.65 \pm 0.91$ & $5.02 \pm 0.9$ & 0.001 \\
\hline TG (mmol/L) & $1.0 \pm 0.71$ & $1.28 \pm 0.69$ & $<0.0001$ \\
\hline $\begin{array}{l}\text { HDL-C } \\
(\mathrm{mmol} / \mathrm{L})\end{array}$ & $1.20 \pm 0.34$ & $1.07 \pm 0.26$ & 0.007 \\
\hline $\begin{array}{l}\text { LDL-C } \\
(\mathrm{mmol} / \mathrm{L})\end{array}$ & $2.96 \pm 0.76$ & $3.32 \pm 0.81$ & $<0.0001$ \\
\hline $\operatorname{ALT}(\mathrm{IU} / \mathrm{L})$ & $\begin{array}{c}23.42 \\
\pm 16.57\end{array}$ & $30.91 \pm 19.24$ & $<0.0001$ \\
\hline $\begin{array}{l}\text { Insulin }(\mu \mathrm{U} / \\
\mathrm{mL})\end{array}$ & $7.46 \pm 6.95$ & $11.87 \pm 11.33$ & $<0.0001$ \\
\hline S\% & $\begin{array}{l}119.31 \\
\pm 56.71\end{array}$ & $91.43 \pm 54.42$ & 0.002 \\
\hline $\mathrm{B} \%$ & $\begin{array}{l}101.52 \\
\pm 54.32\end{array}$ & $110.15 \pm 70.08$ & 0.1 \\
\hline HOMA-IR & $1.12 \pm 0.79$ & $1.66 \pm 1.42$ & 0.002 \\
\hline $\begin{array}{l}\text { Glucose } \\
(\mathrm{mmol} / \mathrm{L})\end{array}$ & $4.97 \pm 0.64$ & $5.91 \pm 1.76$ & $<0.0001$ \\
\hline HbAlc (\%) & $5.63 \pm 0.40$ & $7.58 \pm 1.14$ & $<0.0001$ \\
\hline $\begin{array}{l}\text { Adiponectin } \\
(\mu \mathrm{g} / \mathrm{mL})\end{array}$ & $8.57 \pm 4.42$ & $6.92 \pm 2.86$ & $<0.0001$ \\
\hline
\end{tabular}

Abbreviations: WC: waist circumference; SBP: systolic blood pressure; DBP: diastolic blood pressure; TC: total cholesterol; TG: triglyceride; HDL-C: high-density lipoprotein; LDL-C: low-density lipoprotein; ALT: alanine aminotransferase; $\mathrm{S} \%$ : insulin sensitivity; B\%: beta cell function; HOMA-IR: homeostasis model assessment of insulin resistance; HbAlc: hemoglobin Alc. Data are presented as mean \pm standard deviation.

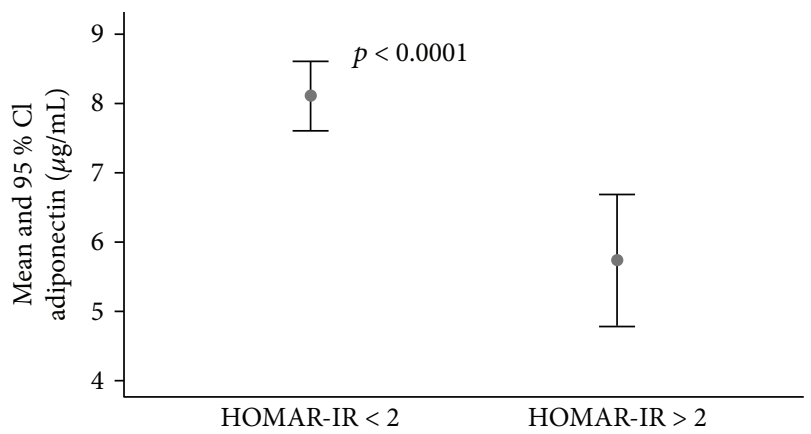

Figure 1: Adiponectin levels in subjects with undiagnosed diabetes grouped by homeostasis model assessment of insulin resistance. $\mathrm{CI}=$ confidence interval.

has been shown to precede a decrease in insulin sensitivity [5] as well as predict progression from normoglycemia to prediabetes [21]. These studies and our findings highlight the potential of adiponectin as a screening tool that could be used to monitor progression from prediabetes to diabetes and associated complications.
TABLE 3: Clinical and anthropometric characteristics of type 2 diabetic subjects grouped by achievement of target HbAlc.

\begin{tabular}{|c|c|c|c|}
\hline $\mathrm{HbAlc}$ & $\begin{array}{c}<53 \mathrm{mmol} / \\
\mathrm{mol}\end{array}$ & $\begin{array}{c}>53 \mathrm{mmol} / \\
\mathrm{mol}\end{array}$ & $\begin{array}{l}\text { p Mann- } \\
\text { Whitney } U\end{array}$ \\
\hline Age & $55.4 \pm 13.5$ & $57.8 \pm 9.4$ & NS \\
\hline $\mathrm{WC}(\mathrm{cms})$ & $102.6 \pm 13.2$ & $107 \pm 12.9$ & NS \\
\hline BMI $\left(\mathrm{kg} / \mathrm{m}^{2}\right)$ & $30.3 \pm 7.7$ & $32.8 \pm 6.0$ & 0.05 \\
\hline SBP $(\mathrm{mm} / \mathrm{Hg})$ & $132 \pm 28$ & $132 \pm 20$ & NS \\
\hline $\mathrm{DBP}(\mathrm{mm} / \mathrm{Hg})$ & $82 \pm 13$ & $82 \pm 12$ & NS \\
\hline $\mathrm{TC}(\mathrm{mmol} / \mathrm{L})$ & $4.88 \pm 1.11$ & $5.02 \pm 1.18$ & NS \\
\hline $\mathrm{TG}(\mathrm{mmol} / \mathrm{L})$ & $1.54 \pm 1.06$ & $1.75 \pm 1.19$ & NS \\
\hline HDL-C (mmol/L) & $1.21 \pm 0.34$ & $1.11 \pm 0.29$ & 0.04 \\
\hline LDL-C (mmol/L) & $3.07 \pm 0.95$ & $3.04 \pm 0.98$ & NS \\
\hline $\operatorname{ALT}(\mathrm{IU} / \mathrm{L})$ & $\begin{array}{c}21.91 \\
\pm 12.72\end{array}$ & $\begin{aligned} & 34.15 \\
\pm & 177.75\end{aligned}$ & 0.02 \\
\hline Insulin $(\mu \mathrm{U} / \mathrm{mL})$ & $\begin{array}{c}11.51 \\
\pm 14.74\end{array}$ & $\begin{array}{l}17.15 \\
\pm 25.48\end{array}$ & NS \\
\hline S\% & $\begin{array}{c}88.05 \\
\pm 41.30\end{array}$ & $\begin{array}{c}73.46 \\
\pm 50.21\end{array}$ & 0.03 \\
\hline $\mathrm{B} \%$ & $\begin{array}{c}77.08 \\
\pm 53.19\end{array}$ & $\begin{array}{l}43.40 \\
\pm 37.69\end{array}$ & $<0.0001$ \\
\hline HOMA-IR & $1.51 \pm 1.04$ & $2.31 \pm 2.0$ & 0.03 \\
\hline Glucose (mmol/L) & $6.73 \pm 2.03$ & $11.23 \pm 4.08$ & $<0.0001$ \\
\hline HbAlc (\%) & $6.34 \pm 0.47$ & $10.69 \pm 2.53$ & $<0.0001$ \\
\hline $\begin{array}{l}\text { Adiponectin }(\mu \mathrm{g} / \\
\mathrm{mL})\end{array}$ & $8.58 \pm 4.5$ & $7.37 \pm 4.35$ & 0.04 \\
\hline
\end{tabular}

Abbreviations: WC: waist circumference; BMI: body mass index; SBP: systolic blood pressure; DBP: diastolic blood pressure; TC: total cholesterol; TG: triglyceride; HDL-C: high-density lipoprotein; LDL-C: low-density lipoprotein; ALT: alanine aminotransferase; S\%: insulin sensitivity; $\mathrm{B} \%$ : beta cell function; HOMA-IR: homeostasis model assessment of insulin resistance; HbAlc: hemoglobin Alc; NS: not significant $(p>0.05)$. Data are presented as mean \pm standard deviation

The usefulness of adiponectin for the detection of the metabolic syndrome had been shown in a previous study [14]. The present study on subjects at high risk of T2DM has shown that adiponectin has good performance characteristics for the detection of previously undiagnosed T2DM. The diagnostic sensitivity, specificity and area under the ROC curve (Figure 2) show that adiponectin could be a useful adjunct for the diagnosis of T2DM in a population screen for T2DM. Even after adjustment for confounding risk factors, the binary logistic regression association of adiponectin with T2DM with an odds ratio of 0.88 further highlights low adiponectin as a strong predictor of incident T2DM [19].

One of the interesting findings in our study is the significant difference in adiponectin concentrations between T2DM subjects with good glycemic control and poor glycemic control (Table 3). The association of higher adiponectin levels with better glycemic control suggests that therapeutic modalities that increase adiponectin levels may be valuable targets for management of T2DM. Methods that enhance or mimic adiponectin levels have been shown to be effective therapeutic strategies for improving diabetes control, treatment of insulin resistance, and other metabolic abnormalities associated with T2DM. Thiazolidinediones are a class of 
TABLE 4: Multivariate regression analysis of the associations of cardiometabolic variables with adiponectin concentration as a dependent variable in subjects screened for type 2 diabetes mellitus.

\begin{tabular}{|c|c|c|c|c|c|c|}
\hline & $\beta$ coefficient & $95 \%$ confidence interval & $p$ & $\beta^{*}$ coefficient & $95 \%$ confidence interval & $p$ \\
\hline WC (cms) & -0.341 & -0.114 to -0.066 & $<0.0001$ & -0.314 & -0.178 to -0.008 & 0.023 \\
\hline BMI $\left(\mathrm{kg} / \mathrm{m}^{2}\right)$ & -0.224 & -0.211 to -0.062 & $<0.0001$ & 0.220 & -.028 to 0.348 & 0.059 \\
\hline $\mathrm{SBP}(\mathrm{mm} / \mathrm{Hg})$ & -0.151 & -0.086 to -0.018 & 0.003 & -0.045 & -0.082 to 0.055 & 0.695 \\
\hline $\mathrm{DBP}(\mathrm{mm} / \mathrm{Hg})$ & -0.160 & -0.138 to -0.033 & 0.002 & -.097 & -0.178 to 0.074 & 0.415 \\
\hline $\mathrm{TC}(\mathrm{mmol} / \mathrm{L})$ & -0.187 & -1.325 to -0.421 & $<0.0001$ & -0.145 & -2.701 to 1.343 & 0.507 \\
\hline TG (mmol/L) & -0.291 & -2.269 to -1.159 & $<0.0001$ & -0.135 & -1.927 to 0.346 & 0.172 \\
\hline HDL-C (mmol/L) & 0.338 & 3.170 to 5.578 & $<0.0001$ & 0.309 & 1.397 to 6.588 & 0.003 \\
\hline LDL-C (mmol/L) & -0.240 & -1.809 to -0.759 & $<0.0001$ & -0.161 & -2.865 to 1.085 & 0.376 \\
\hline ApoA1 (g/L) & 0.136 & 0.169 to 3.673 & 0.032 & -.462 & -13.608 to -2.371 & 0.006 \\
\hline Apo B (g/L) & -0.269 & -4.647 to -1.995 & $<0.0001$ & -0.271 & -1.165 to -0.502 & $<0.0001$ \\
\hline HOMA-IR & -0.252 & -1.550 to -0.548 & $<0.0001$ & -0.166 & -1.377 to -0.012 & 004 \\
\hline Glucose (mmol/L) & -0.173 & -1.247 to -0.352 & $<0.0001$ & -0.097 & -0.791 to 0.039 & 0.076 \\
\hline $\mathrm{HbAlc}(\mathrm{mmol} / \mathrm{mol})$ & -0.061 & -0.050 to 0.012 & 0.227 & 0.055 & -0.672 to 1.286 & 0.054 \\
\hline
\end{tabular}

Abbreviations: WC: waist circumference; BMI: body mass index; TC: total cholesterol; TG: triglyceride; HDL-C: high-density lipoprotein; LDL-C: low-density lipoprotein; Apo A1: apolipoprotein A1; Apo B: apolipoprotein B; HbA1c: hemoglobin A1c; SBP: systolic blood pressure; DBP: diastolic blood pressure; HOMA-IR: homeostasis model assessment of insulin resistance; $\beta^{*}$ : inclusion of all cardiometabolic variables in the regression model.

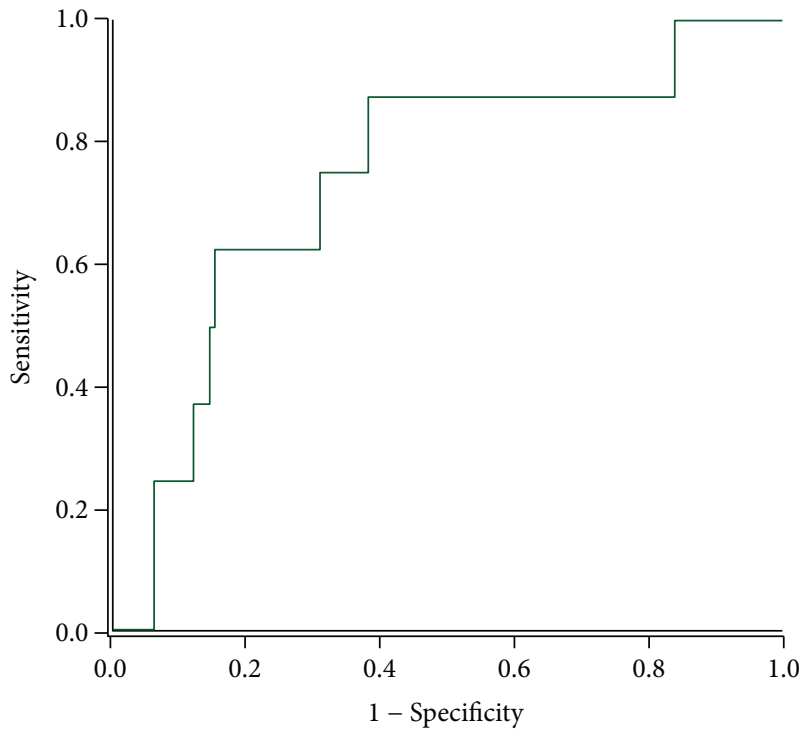

FIGURE 2: Receiver operating characteristic analysis of the usefulness of adiponectin for the diagnosis of type 2 diabetes mellitus.

antidiabetic drugs, known to exert an insulin-sensitizing effect, mediated partly by upregulating plasma adiponectin levels [2]. Several other drugs like statins, angiotensinconverting enzyme inhibitors, and angiotensin II receptor blockers that target adiponectin synthesis have also been reported to improve glucose tolerance and ameliorate insulin resistance [22]. However, although adiponectin is present at relatively high amounts in circulation and can be easily measured, the efficacy of adiponectin as a potentially useful therapeutic agent needs to be demonstrated experimentally and in clinical trials.

One of the main limitations of this study is that it is a cross-sectional study which does not help establish a causal relation between low adiponectin and T2DM development. Additionally, study participants used in our study were those at high risk for developing T2DM; thus, the associations observed with adiponectin and T2DM risk may not be applicable to those without family history of T2DM. Our study does not provide data on adiponectin multimeric complexes particularly high molecular weight (HMW) adiponectin, which has been shown to be the most biologically active form. However, others have reported similar associations of both total adiponectin and HMW with incident T2DM [23] and cardiometabolic risk factors [24].

\section{Conclusion}

Adiponectin levels are associated with incident diabetes and glycemic control and could be useful adjuncts for screening for IR and T2DM. The significant associations of adiponectin levels with clinical and cardiometabolic parameters reveal its potential as a biomarker in assessment of prediabetic state and T2DM screening.

\section{Disclosure}

An abstract of this manuscript was presented as a poster (A-176) at the 2014 Annual and Scientific Meeting of the American Association of Clinical Chemists in Chicago, IL, USA.

\section{Conflicts of Interest}

The authors declare that they have no conflict of interests.

\section{Acknowledgments}

The authors gratefully acknowledge the contributions of Dr. Hisham Al Mohammedy (recruitment of study subjects), 
Cynthia Pinto and Chetana Naidu (laboratory work and data entry), and Dr. Jincy Issac (preparation of the manuscript). This work was supported by the Kuwait Foundation for the Advancement of Sciences (KFAS) (Grant no. 2011-1302-01).

\section{References}

[1] W. S. Yang, W. J. Lee, T. Funahashi et al., "Plasma adiponectin levels in overweight and obese Asians," Obesity Research, vol. 10, no. 11, pp. 1104-1110, 2002.

[2] T. Kadowaki, T. Yamauchi, N. Kubota, K. Hara, K. Ueki, and $\mathrm{K}$. Tobe, "Adiponectin and adiponectin receptors in insulin resistance, diabetes, and the metabolic syndrome," The Journal of Clinical Investigation, vol. 116, no. 7, pp. 1784-1792, 2006.

[3] C. Weyer, T. Funahashi, S. Tanaka et al., "Hypoadiponectinemia in obesity and type 2 diabetes: close association with insulin resistance and hyperinsulinemia," The Journal of Clinical Endocrinology and Metabolism, vol. 86, no. 5, pp. 1930-5, 2001.

[4] N. Ouchi, S. Kihara, Y. Arita et al., "Novel modulator for endothelial adhesion molecules: adipocyte-derived plasma protein adiponectin," Circulation, vol. 100, no. 25, pp. 2473-2476, 1999.

[5] N. Stefan, B. Vozarova, T. Funahashi et al., "Plasma adiponectin concentration is associated with skeletal muscle insulin receptor tyrosine phosphorylation, and low plasma concentration precedes a decrease in whole-body insulin sensitivity in humans," Diabetes, vol. 51, no. 6, pp. 1884-1888, 2002.

[6] S. H. Han, I. Sakuma, E. K. Shin, and K. K. Koh, "Antiatherosclerotic and anti-insulin resistance effects of adiponectin: basic and clinical studies," Progress in Cardiovascular Diseases, vol. 52, no. 2, pp. 126-140, 2009.

[7] B. B. Duncan, M. I. Schmidt, J. S. Pankow et al., "Adiponectin and the development of type 2 diabetes: the atherosclerosis risk in communities study," Diabetes, vol. 53, no. 9, pp. 2473-2478, 2004.

[8] S. Aleidi, A. Issa, H. Bustanji, M. Khalil, and Y. Bustanji, "Adiponectin serum levels correlate with insulin resistance in type 2 diabetic patients," Saudi Pharmaceutical Journal, vol. 23, no. 3, pp. 250-256, 2015.

[9] M. Adamczak, A. Wiecek, T. Funahashi, J. Chudek, F. Kokot, and Y. Matsuzawa, "Decreased plasma adiponectin concentration in patients with essential hypertension," American Journal of Hypertension, vol. 16, no. 1, pp. 72-75, 2003.

[10] M. Matsubara, S. Maruoka, and S. Katayose, "Decreased plasma adiponectin concentrations in women with dyslipidemia," The Journal of Clinical Endocrinology and Metabolism, vol. 87, no. 6, pp. 2764-2769, 2002.

[11] T. Kazumi, A. Kawaguchi, K. Sakai, T. Hirano, and G. Yoshino, "Young men with high-normal blood pressure have lower serum adiponectin, smaller LDL size, and higher elevated heart rate than those with optimal blood pressure," Diabetes Care, vol. 25, no. 6, pp. 971-976, 2002.

[12] N. A. Abdella and O. A. Mojiminiyi, "Cross-sectional study of the determinants and associations of sex hormone-binding globulin concentrations in first degree relatives (FDR) of patients with type 2 diabetes mellitus," Diabetes Research and Clinical Practice, vol. 133, pp. 159-167, 2017.

[13] American Diabetes Association, "Standards of medical care in diabetes," Diabetes Care, vol. 40, Supplement 1, pp. S1-S135, 2017.
[14] O. A. Mojiminiyi, N. A. Abdella, M. al Arouj, and A. Ben Nakhi, "Adiponectin, insulin resistance and clinical expression of the metabolic syndrome in patients with type 2 diabetes," International Journal of Obesity, vol. 31, no. 2, pp. 213-220, 2007.

[15] W. T. Friedewald, R. I. Levy, and D. S. Fredrickson, "Estimation of the concentration of low-density lipoprotein cholesterol in plasma, without use of the preparative ultracentrifuge," Clinical Chemistry, vol. 18, no. 6, pp. 499-502, 1972.

[16] M. Santaniemi, Y. A. Kesaniemi, and O. Ukkola, "Low plasma adiponectin concentration is an indicator of the metabolic syndrome," European Journal of Endocrinology, vol. 155, no. 5, pp. 745-750, 2006.

[17] S. Yamamoto, Y. Matsushita, T. Nakagawa, T. Hayashi, M. Noda, and T. Mizoue, "Circulating adiponectin levels and risk of type 2 diabetes in the Japanese," Nutrition \& Diabetes, vol. 4, no. 8, article e130, 2014.

[18] M. J. Kim, K. H. Yoo, H. S. Park et al., "Plasma adiponectin and insulin resistance in Korean type 2 diabetes mellitus," Yonsei Medical Journal, vol. 46, no. 1, pp. 42-50, 2005.

[19] S. Lindberg, J. S. Jensen, M. Bjerre et al., “Adiponectin, type 2 diabetes and cardiovascular risk," European Journal of Preventive Cardiology, vol. 22, no. 3, pp. 276-283, 2015.

[20] F. Pellme, U. Smith, T. Funahashi et al., "Circulating adiponectin levels are reduced in nonobese but insulin-resistant firstdegree relatives of type 2 diabetic patients," Diabetes, vol. 52, no. 5, pp. 1182-1186, 2003.

[21] Y. Jiang, I. Owei, J. Wan, S. Ebenibo, and S. Dagogo-Jack, "Adiponectin levels predict prediabetes risk: the pathobiology of prediabetes in a biracial cohort (POP-ABC) study," $B M J$ Open Diabetes Research \& Care, vol. 4, no. 1, article e000194, 2016.

[22] M. Furuhashi, N. Ura, K. Higashiura et al., "Blockade of the renin-angiotensin system increases adiponectin concentrations in patients with essential hypertension," Hypertension, vol. 42, no. 1, pp. 76-81, 2003.

[23] J. R. Kizer, A. M. Arnold, D. Benkeser et al., "Total and high-molecular-weight adiponectin and risk of incident diabetes in older people," Diabetes Care, vol. 35, no. 2, pp. 415-423, 2012.

[24] B. Elisha, S. Ziai, A. D. Karelis et al., "Similar associations of total adiponectin and high molecular weight adiponectin with cardio-metabolic risk factors in a population of overweight and obese postmenopausal women: a MONET study," Hormone and Metabolic Research, vol. 42, no. 08, pp. 590594, 2010. 


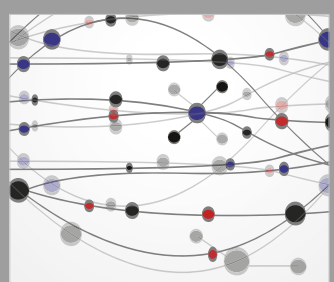

The Scientific World Journal
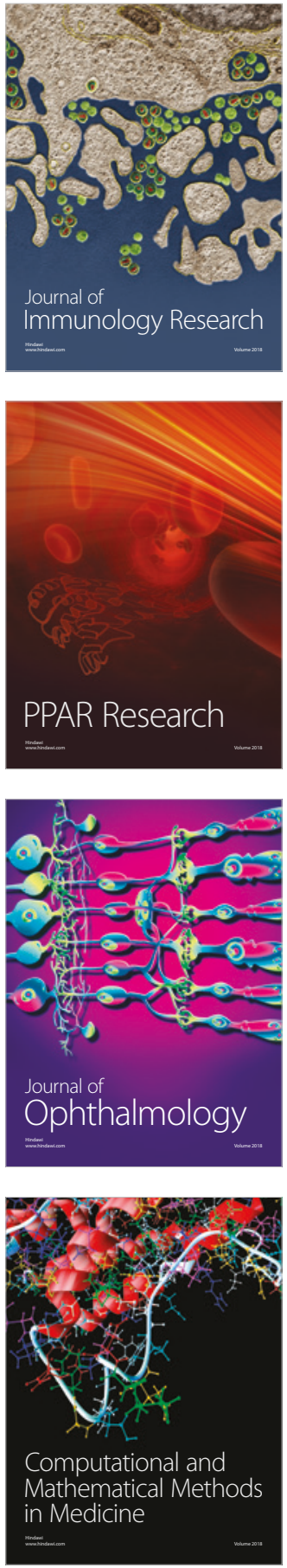

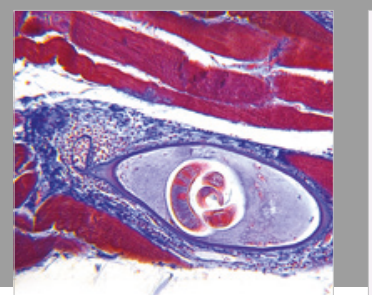

Gastroenterology Research and Practice

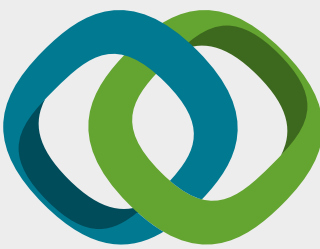

\section{Hindawi}

Submit your manuscripts at

www.hindawi.com
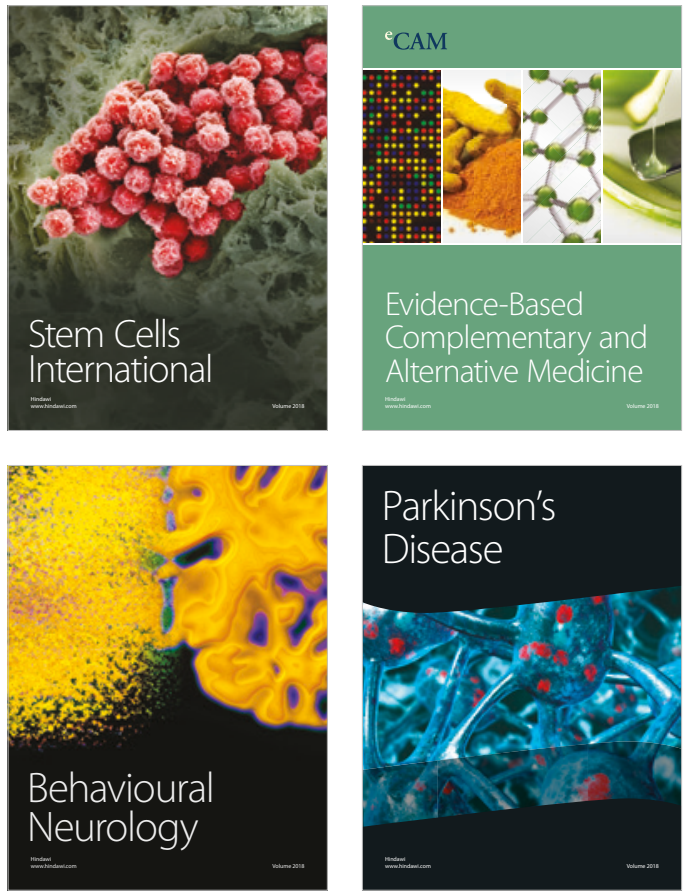

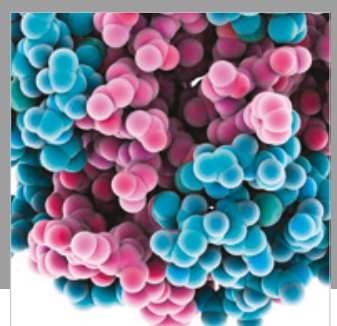

ournal of

Diabetes Research

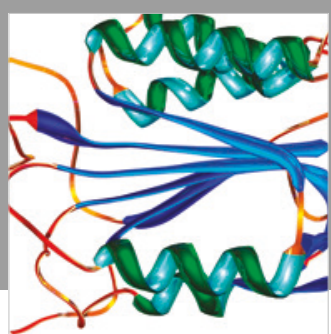

Disease Markers
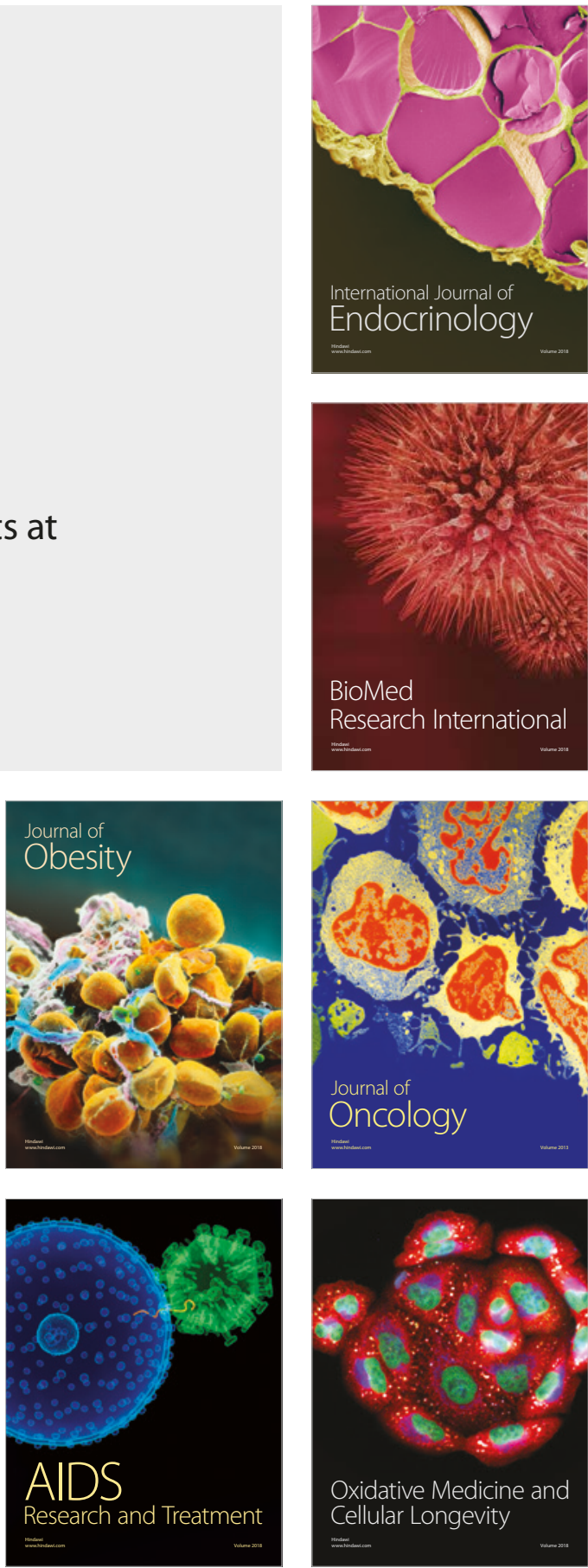